\title{
Chemical Modification of Transducin with Dansyl Chloride Hinders Its Binding to Light-activated Rhodopsin
}

\author{
Ana Kosoy ${ }^{\dagger, \S}$, Carolina Möller ${ }^{\dagger, \|,}$ Deisy Perdomo ${ }^{\star}$ and José Bubis ${ }^{\dagger * *}$ \\ 'Departamento de Química, 'Departamento de Biología Celular, Universidad Simón Bolívar, Caracas 1081-A, Venezuela
}

Received 27 June 2003, Accepted 13 August 2003

\begin{abstract}
Transducin (T), the heterotrimeric guanine nucleotide binding protein in rod outer segments, serves as an intermediary between the receptor protein, rhodopsin, and the effector protein, cGMP phosphodiesterase. Labeling of T with dansyl chloride (DnsCl) inhibited its lightdependent guanine nucleotide binding activity. Conversely, DnsCl had no effect on the functionality of rhodopsin. Approximately 2-3 mol of DnsCl were incorporated per mole of T. Since fluoroaluminate was capable of activating DnsCl-modified T, this lysine-specific labeling compound did not affect the guanine nucleotide-binding pocket of $T$. However, the labeling of $\mathrm{T}$ with DnsCl hindered its binding to photoexcited rhodopsin, as shown by sedimentation experiments. Additionally, rhodopsin completely protected against the DnsCl inactivation of $T$. These results demonstrated the existence of functional lysines on $\mathrm{T}$ that are located in the proximity of the interaction site with the photoreceptor protein.
\end{abstract}

Keywords: Chemical modification, G-protein-coupled signaling, Group-specific labeling, Rhodopsin, Transducin, Visual process

\section{Introduction}

Heterotrimeric guanine nucleotide binding proteins (Gproteins), which consist of three subunits $(\alpha, \beta$, and $\gamma)$, act as molecular switches in which the information flow depends on

${ }^{\S}$ Present address: Cancer Center, Mount Sinai Medical School, One Gustave L. Levy Place, Box 1020, New York, NY 10029, USA

"Present address: Florida Atlantic University, 777 Glades Road, Boca Raton, FL 33431-0991, USA

*To whom correspondence should be addressed. Tel: 58-212-906-4219; Fax: 58-212-906-3064

E-mail: jbubis@usb.ve whether the bound nucleotide is GDP (“off") or GTP (“on") (Hamm, 1998). G-proteins are activated by G-protein-coupled receptors (GPCRs), which contain a common "central core" that is composed of seven transmembrane $\alpha$-helical segments (Bockaert and Pin, 1999). In the activated form, the cytoplasmic domains of GPCRs are competent for binding to specific G-proteins, leading to subsequent catalytic GTP/GDP exchange on the $\alpha$-subunits. Consequently, the G-proteins dissociate to form $\alpha$-subunits that are complexed to GTP and $\beta \gamma$-dimers. The activation and dissociation of G-proteins in turn lead to the stimulation of effector enzymes, alterations in the concentration of cellular second messenger levels, or opening of ion channels. Finally, the active $\alpha$-subunits are kinetically turned off by their intrinsic GTPase activities, which are highly regulated by the bound effector and regulator of G-protein signaling proteins (Berman et al., 1996; He et al., 1998). Following GTP hydrolysis, the GDP-bound $\alpha$-subunits reassociate with their corresponding $\beta \gamma$-complexes, and the reconstituted inactive G-proteins are primed for a new cycle. Moreover, the receptor activation is countered by the phosphorylation of activated receptors by G-protein-coupled receptor kinases, followed by the binding of an arrestin molecule, which desensitizes receptor signaling (Carman and Benovic, 1998). A high-resolution structural analysis of several nucleotide-bound forms of G-protein $\alpha$-subunits (Noel et al., 1993; Coleman et al., 1994; Lambright et al., 1994; Mixon et al., 1995) and of $\alpha$-subunits complexes with regulatory proteins (Tesmer et al., 1997; Slep et al., 2001) has provided insights into the key conformational changes that are required for the G-protein function.

The vertebrate visual process in retinal rods is a typical example of a G-protein-coupled signaling system (Pugh et al., 1999). The photoreceptor protein rhodopsin (R) mediates scotopic vision and is a unique member among GPCRs in that it contains an intrinsic inverse-agonist, the 11-cis-retinal (Hargrave, 2001). Photon absorption results in retinal isomerization to the all-trans configuration. Such a trigger by the chromophore corresponds to the binding of a diffusible ligand to other GPCRs. $\mathrm{R}$ defines the so-called Family 1 
GPCRs, which share primary structural homology (Bockaert and Pin, 1999). It was the first GPCR to be sequenced by amino acid sequencing (Ovchinnikov, 1982; Hargrave et al., 1983), the first to be cloned (Nathans and Hogness, 1983, 1984), the first to be crystallized (Okada et al., 2000), and the first to yield a crystal structure (Palczewski et al., 2000). Electron cryomicroscopy on the two-dimensional crystals of bovine rhodopsin also provided the first direct visualization of the seven transmembrane helices of GPCR (Schertler et al., 1993; Unger et al., 1997). Light-induced structural changes in $\mathrm{R}$ lead to an active intermediate, metarhodopsin II, which stabilizes its interaction with the retinal G-protein transducin (T) and activates it. Photoexcited $\mathrm{R}\left(\mathrm{R}^{*}\right)$ catalyzes the GTP/ GDP exchange on $\mathrm{T}$, which initiates conformational changes in the protein that results in the dissociation of its GTP-bound $\alpha$-subunit $\left(\mathrm{T}_{\alpha}\right)$ from the $\beta \gamma$-complex $\left(\mathrm{T}_{\beta \gamma}\right) . \mathrm{T}_{\alpha}-\mathrm{GTP}$, in turn, activates a potent cGMP phosphodiesterase. The reduction in intracellular cGMP concentration leads to the closing of cGMP-gated cation channels in the plasma membrane of the rod cell, which causes a graded hyperpolarization of the photoreceptor cell and generation of a neuronal signal. The amplification and regulation of the light response is of great physiological importance (Baylor, 1996; Lamb, 1996).

$\mathrm{T}$ is characterized by several functional sites, which include its subunits interaction domains, the magnesium and guanine nucleotide binding regions, and contact sites for several proteins of the visual cascade: R, cGMP phosphodiesterase, phosducin (Wilkins et al., 1996; Chen and Lee, 1997), and the complex between the regulator of the G-protein signaling 9 and the type 5 G-protein $\beta$-subunit (He et al., 1998; Makino et al., 1999). Group-specific labeling and chemical cross-linking techniques have been employed to identify and characterize functional residues in T (Bubis and Khorana, 1990; Bubis et al., 1995, 2001; Ortiz and Bubis, 2001; Millán and Bubis, 2002). Pyridoxal 5'-phosphate (PLP) was also successfully utilized as an affinity label for the active site of T (Jaffé and Bubis, 2002). Here we performed modification experiments using dansyl chloride (DnsCl) to probe for functionally important lysines on $\mathrm{T}$. We discovered that $\mathrm{DnsCl}$ inhibited the light-dependent guanine nucleotide binding activity of $\mathrm{T}$ by hindering its association to $\mathrm{R}^{*}$.

\section{Materials and Methods}

Materials Bovine eyes were purchased from the nearest abattoir (Matadero Caracas, CA). Retinas were extracted in the dark, under dim red light, and kept frozen at $-70^{\circ} \mathrm{C}$ until use. The reagents were obtained from the following sources: $\beta, \gamma$-imido- $\left[{ }^{3} \mathrm{H}\right]$ guanosine 5 'triphosphate $\quad\left(\left[8{ }^{3} \mathrm{H}\right] \mathrm{GMPpNp}\right) \quad(15.6 \mathrm{Ci} / \mathrm{mmol}), \quad$ Amersham (Piscataway, USA); DnsCl, L-lysine, tosylphenyl alanyl chloromethyl ketone (TPCK)-treated trypsin, Sigma (St. Louis, USA); DEAE-Sepharose, Pharmacia (Uppsala, Sweden). All of the other chemicals were of the highest quality grade available.
Preparation of rod outer segments and urea-washed membranes Rod outer segments (ROS) were isolated from frozen bovine retinas (Bubis, 1998). The ROS membranes were washed with $5 \mathrm{M}$ urea to remove peripheral proteins (Shichi and Somers, 1978). The R concentration was calculated from UV/ visible absorption spectra (Wald and Brown, 1953).

Purification of T T was purified from ROS membranes that were prepared under room light, using ion-exchange chromatography on DEAE-Sepharose (Bubis, 1995).

Binding of $\left[{ }^{3} \mathbf{H}\right]$ GMPpNp to $\mathbf{T}$ Guanine nucleotide binding to $\mathrm{T}$ was measured by a millipore filter paper assay using the nonhydrolyzable analog of GTP, $\left[{ }^{3} \mathrm{H}\right] \mathrm{GMPpNp}$. The binding reaction was carried out in Buffer A [50 mM Tris- $\mathrm{HCl}(\mathrm{pH} 7.5)$, $5 \mathrm{mM}$ magnesium acetate, $100 \mathrm{mM} \mathrm{NaCl}$ and $5 \mathrm{mM} \beta$ mercaptoethanol] containing $0.2 \mu \mathrm{M}$ of $\mathrm{T}, 0.1 \mu \mathrm{M} \mathrm{R}$ (as ureawashed ROS membranes), and a fixed concentration of $\left[{ }^{3} \mathrm{H}\right]$ GMPpNp (0.2 $\mu \mathrm{M})$ (Bubis et al., 1993; Ortiz and Bubis, 2001). Following incubation for $1 \mathrm{~h}$, at $4^{\circ} \mathrm{C}$, under room light, a $100 \mu \mathrm{l}$ aliquot of the reaction mixture was transferred to a filter reservoir $(0.45 \mu \mathrm{m}$ Millipore HA filter), containing $5 \mathrm{ml}$ of ice-cold Buffer A. The blanks were measured in the absence of $\mathrm{T}$ and subtracted from all of the values. In all of the cases, the average value, resulting from triplicate determinations, was reported.

Modifications of T lysyl residues with DnsCl Stock solutions of $\mathrm{DnsCl}$ were freshly prepared in acetonitrile. $\mathrm{T}(0.2 \mu \mathrm{M})$ was incubated for $1 \mathrm{~h}$ at $4^{\circ} \mathrm{C}$ with various concentrations of $\mathrm{DnsCl}(0-40$ $\mathrm{mM}$ ) in $100 \mathrm{mM}$ Tris ( $\mathrm{pH} \mathrm{8)}$. Additionally, the time course of modification was determined by incubating $\mathrm{T}$ with $5 \mathrm{mM} \mathrm{DnsCl}$ in $100 \mathrm{mM}$ Tris $(\mathrm{pH} 8)$. At designated time intervals (0-60 min), the reactions were terminated by the addition of $30 \mathrm{mM}$ lysine and 20 $\mathrm{mM} \beta$-mercaptoethanol. The function of the modified $\mathrm{T}$ was assessed, determining its remaining light-dependent $\left[{ }^{3} \mathrm{H}\right] \mathrm{GMPpNp}$ binding activity. Scanning the absorption spectra of the DnsClmodified $\mathrm{T}$ between 200 and $500 \mathrm{~nm}$, and subtracting the corresponding absorbance of the untreated protein, spectrophotometrically established the stoichiometry of DnsClincorporation on $\mathrm{T}$. The dansyl groups that were covalently bound to $\mathrm{T}$ were estimated by employing the following two methods: (i) by directly using the molar extinction coefficient of dansyl glycine in water - $\varepsilon=4,300 \mathrm{M}^{-1} \mathrm{~cm}^{-1}$ at $327.25 \mathrm{~nm}$ - (Chen, 1968; Du et al., 1998) and (ii) by interpolation on calibration curves prepared using either dansyl glycine or the bis-dansyl derivative of lysine as standards.

Interaction assay between DnsCl-modified T and $\mathbf{R}^{*} \quad \mathrm{~T}(4 \mu \mathrm{M})$ was incubated with $5 \mathrm{mM}$ DnsCl in $100 \mathrm{mM}$ Tris (pH 8). Following an $1 \mathrm{~h}$-incubation at $4^{\circ} \mathrm{C}$, the reaction was terminated with $30 \mathrm{mM}$ lysine and $20 \mathrm{mM} \beta$-mercaptoethanol. Parallel experiments, in which $\mathrm{T}$ was incubated with just the buffer or with $\mathrm{DnsCl}$ that was previously titrated with $30 \mathrm{mM}$ lysine and $20 \mathrm{mM} \quad \beta$ mercaptoethanol, were included as the controls. T, at this step, was denominated $\mathrm{T}$ (Lys-X), where $\mathrm{X}=\mathrm{H}$ or the labeling group. An aliquot of the urea-washed ROS membranes, containing 3.5 $\mu \mathrm{M} \mathrm{R}$, 
was mixed with $\mathrm{T}$ (Lys-X) $(2.4 \mu \mathrm{M})$ in an isotonic solution [5 mM Tris- $\mathrm{HCl}$ (pH 7.5), $100 \mathrm{mM} \mathrm{NaCl}, 5 \mathrm{mM}$ magnesium acetate, and 5 $\mathrm{mM} \beta$-mercaptoethanol]. To allow the formation of the transducinphotoactivated rhodopsin complex $\left(\mathrm{T}: \mathrm{R}^{*}\right)$, the mixture was cooled on ice, kept in the dark for $10 \mathrm{~min}$, then illuminated for $1 \mathrm{~min}$ with bright light, and held for $1 \mathrm{~h}$ under room light at $4^{\circ} \mathrm{C}$. After the first centrifugation step (30 min at 40,000 rpm, RP120AT-203 fixed angle rotor Sorvall RCM120 microultracentrifuge) the supernatant (S-ISO), was carefully removed. The bleached pellet was washed with a hypotonic buffer $[5 \mathrm{mM}$ Tris- $\mathrm{HCl}(\mathrm{pH}$ 7.5), $5 \mathrm{mM}$ magnesium acetate, and $5 \mathrm{mM} \beta$-mercaptoethanol] and centrifuged as before in order to remove residual soluble proteins. The supernatant (S-HYPO) was saved for subsequent analyses, while the pellet was washed with $150 \mathrm{mM}$ GTP in a hypotonic buffer (PrGTP). Then, Pr-GTP was centrifuged, and both the resultant supernatant (S-GTP) and resuspended final pellet (Pf) were stored for later examination. Aliquots of T (Lys-X), S-ISO, S-HYPO, PrGTP, S-GTP, and Pf were analyzed by SDS-polyacrylamide gel electrophoresis (SDS-PAGE) and Western blot.

\section{Assay of $\mathbf{T}$ functionality in the $\mathbf{T}: \mathbf{R} *$ complex incubated with} DnsCl $\mathrm{T}(1.4 \mu \mathrm{M})$ was incubated with dark-depleted ROS membranes $(5.6 \mu \mathrm{M} \mathrm{R})$ for $1 \mathrm{~h}$ at $4^{\circ} \mathrm{C}$ under light in order to form the $\mathrm{T}: \mathrm{R}^{*}$ complex. This suspension was centrifuged to remove residual free $\mathrm{T}$ (30 $\mathrm{min}$ at 40,000 $\mathrm{rpm}, \mathrm{RP120AT}-203$ fixed angle rotor, Sorvall RCM120 microultracentrifuge). The pellet was resuspended in an isotonic solution containing $5 \mathrm{mM} \mathrm{DnsCl}$. Following incubation for $1 \mathrm{~h}$, the reaction was terminated with 30 $\mathrm{mM}$ lysine and $20 \mathrm{mM} \beta$-mercaptoethanol. This incubation was performed at $4^{\circ} \mathrm{C}$ in order to maintain the metarhodopsin II photointermediate. The control experiments were carried out in which the pellet, containing the $T: R^{*}$ complex, was either incubated with a buffer or treated with $\mathrm{DnsCl}$ that was quenched with $30 \mathrm{mM}$ lysine and $20 \mathrm{mM} \beta$-mercaptoethanol. This sample was denominated $\mathrm{Pr}-1$ (Lys-X), where $\mathrm{X}=\mathrm{H}$ or the labeling group. The treated membranes were initially washed with a hypotonic buffer to release the free $\mathrm{DnsCl}$ and residual soluble proteins. After centrifugation, we obtained the S-1 supernatant and corresponding pellet (Pr-2). This wash was repeated to yield the S-2 supernatant. The release of $\mathrm{T}$ was examined by washing the resulting pellet with a hypotonic buffer containing $150 \mathrm{mM}$ GTP. Centrifugation of the GTP resuspended pellet yielded a supernatant (S-GTP) and a final pellet (Pf). Aliquots of Pr-1 (Lys-X), S-1, Pr-2, S-2, S-GTP, and Pf were analyzed by SDS-PAGE and Western blot.

\section{Limited trypsin proteolysis of DnsCl modified- $\mathrm{T}$ in the presence} of fluoroaluminate Fluoroaluminate $\left(30 \mu \mathrm{M} \mathrm{AlCl} \mathrm{Al}_{3}\right.$ and $10 \mathrm{mM}$ $\mathrm{NaF}$ ) was added to $15 \mu \mathrm{g}$ of untreated or DnsCl-modified $\mathrm{T}$. Following an incubation for $1 \mathrm{~h}$ on ice, the samples were digested with TPCK-treated trypsin using a ratio of $1: 20(\mathrm{w} / \mathrm{w})$ between protease and $\mathrm{T}$. The aliquots that contained $5 \mu \mathrm{g}$ of $\mathrm{T}$ were withdrawn at various time intervals $(0-60 \mathrm{~min})$. Digestions were terminated by the addition of a SDS-PAGE sample buffer (Laemmli, 1970). Subsequently, the samples were boiled for $20 \mathrm{~min}$, and the protein fragments were resolved by SDS-PAGE. Then, the gels were either stained or analyzed by Western blotting.

Other procedures The protein concentration was measured according to Bradford (1976), using bovine serum albumin as the protein standard. SDS-PAGE was carried out on 1.5-mm thick slab gels containing 10 or $15 \%$ polyacrylamide (Laemmli, 1970). Silver nitrate was used for the protein staining. For the Western blot analyses, the proteins were electrotransferred from the gels to nitrocellulose filters (Towbin et al., 1979). For immunodetection, the filters were incubated with polyclonal antibodies against bovine $\mathrm{T}$ (dilution $1: 1,000$ ) that was prepared in mice (Bubis et al., 1993). These antibodies preferentially recognize $T_{\alpha}$ but have some crossreactivity with $\mathrm{R}$. The antigenically-reacting polypeptides were then treated with alkaline phosphatase-conjugated secondary antibodies against mouse $\operatorname{IgG}$ at a dilution of $1: 5,000$. Finally, the bands were visualized with 5-bromo-4-chloro-3-indolyl phosphate and nitro blue tetrazolium as substrates.

\section{Results}

Inactivation of $\mathrm{T}\left[{ }^{3} \mathrm{H}\right] \mathrm{GMPpNp}$ binding activity by $\mathrm{DnsCl}$ The effect of different concentrations of $\mathrm{DnsCl}$ on the guanine nucleotide binding activity of $\mathrm{T}$ is illustrated in Fig. 1a. When $\geq 5 \mathrm{mM}$ DnsCl was added to $\mathrm{T}$, we observed a $95 \%$ inhibition on its light-dependent GMPpNp binding capacity (Fig. 1a). Additionally, incubation of $\mathrm{T}$ with up to $8 \%$ acetonitrile, which was the highest concentration that was present in the experiments, where various amounts of $\mathrm{DnsCl}$ were used, produced no effect on the functional activity of the protein (data not shown).

The labeling kinetics of $\mathrm{T}$ by $\mathrm{DnsCl}$ were also determined. At corresponding times, the reactions were stopped by the addition of $30 \mathrm{mM}$ lysine and $20 \mathrm{mM} \beta$-mercaptoethanol, and assayed for GMPpNp binding. As seen in Fig. 1b, the incubation of T with $5 \mathrm{mM}$ DnsCl led to an inactivation of the light-dependent guanine nucleotide binding activity of the protein in about $10 \mathrm{~min}$. However, the protein function was unaffected when $\mathrm{T}$ was treated with $\mathrm{DnsCl}$ that was previously titrated with $30 \mathrm{mM}$ lysine and $20 \mathrm{mM} \beta$ mercaptoethanol. Also shown is a control sample of T, which was not treated with the modification reagent and, as expected, retained full activity.

The molar quantity of modified lysine residues on $\mathrm{T}$ was established by spectrophotometric analysis. A marked spectral change was observed when the absorption spectra of $\mathrm{T}$ and DnsCl-labeled T were compared. The modification of $\mathrm{T}$ with DnsCl caused an increase in absorbance that peaked at $\lambda_{\max }$ of $311.5 \mathrm{~nm}$ (data not shown). The dansyl groups that were covalently bound to $\mathrm{T}$ were estimated by using the molar extinction coefficient of dansyl glycine (data not included). In addition, calibration curves were also prepared using either dansyl glycine or the bis-dansyl derivative of lysine to empirically assess the number of modified residues on $\mathrm{T}$ (data not shown). The stoichiometry of incorporation was determined to be $2.60 \pm 0.56 \mathrm{~mol}$ of $\mathrm{DnsCl}$ bound per mole of $\mathrm{T}$. Interestingly, the resulting $\lambda_{\max }$ for the DnsCl-modified $\mathrm{T}$ was slightly shifted with respect to the value for dansyl glycine. This suggests that the incorporated dansyl groups 

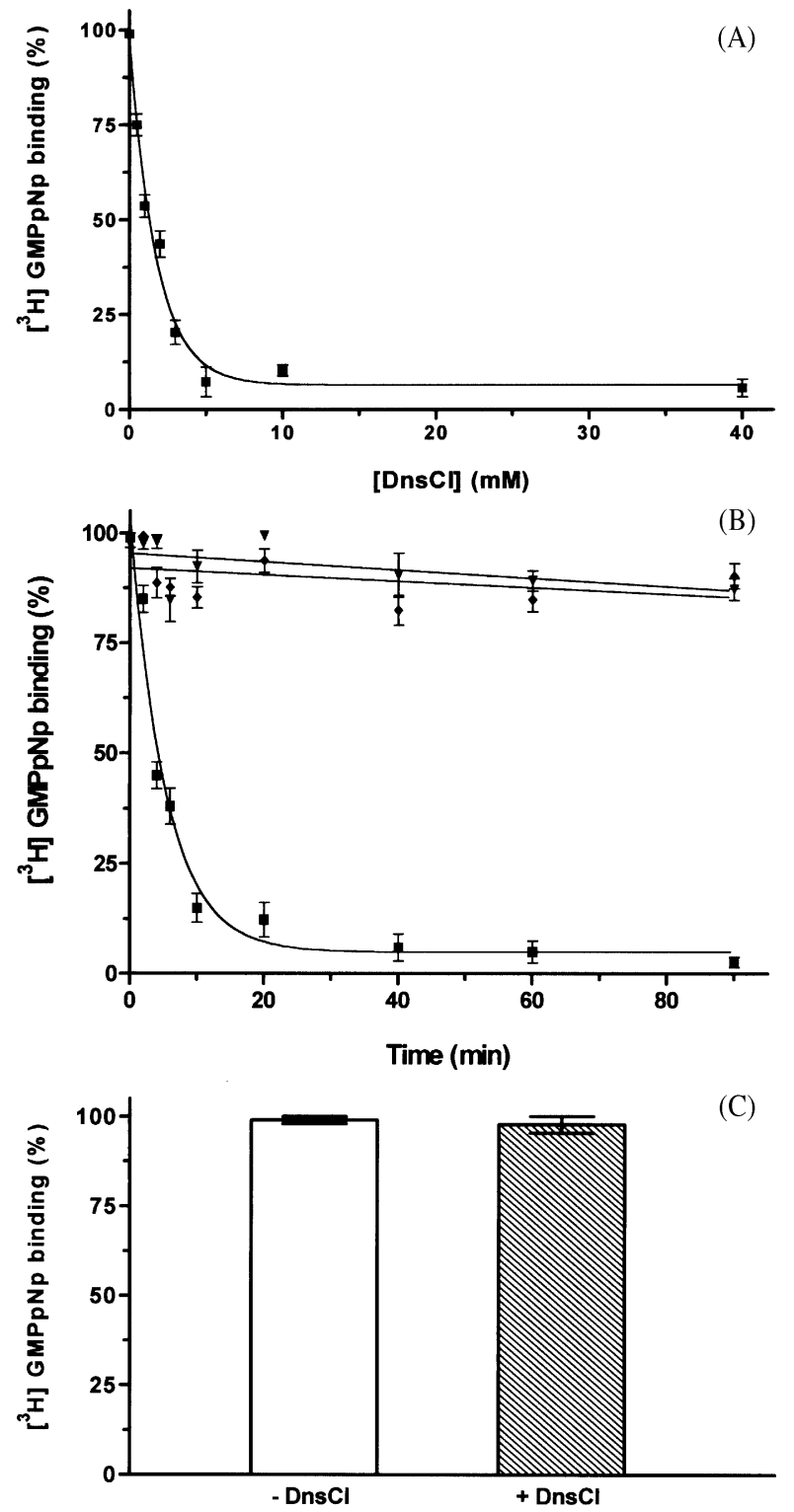

Fig. 1. Effect of DnsCl on the functional activities of $\mathrm{T}$ and $\mathrm{R}$. (A) $\mathrm{T}$ was incubated with various concentrations of $\mathrm{DnsCl}(\boldsymbol{\square})$. Its remaining light-dependent GMPpNp binding activity was assayed in the presence of $\mathrm{R}$. (B) $\mathrm{T}$ was treated with $5 \mathrm{mM}$ $\mathrm{DnsCl}(\boldsymbol{\square}), 5 \mathrm{mM} \mathrm{DnsCl}$ previously titrated with $30 \mathrm{mM}$ lysine, and $20 \mathrm{mM} \beta$-mercaptoethanol $(\boldsymbol{\nabla})$, or with just the buffer $(\boldsymbol{\nabla})$. At the indicated time intervals, the reactions were terminated with $30 \mathrm{mM}$ lysine and $20 \mathrm{mM} \beta$-mercaptoethanol and assayed for its $\mathrm{R}^{*}$-dependent GMPpNp binding activity. (C) $\mathrm{R}$, in the form of urea-washed ROS membranes, was treated with $5 \mathrm{mM}$ $\mathrm{DnsCl}(+\mathrm{DnsCl})$. Control samples were also included (-DnsCl). Following incubation for $1 \mathrm{~h}$ at $4^{\circ} \mathrm{C}$, the reactions were terminated with $30 \mathrm{mM}$ lysine and $20 \mathrm{mM} \beta$-mercaptoethanol. The samples were used to induce the photodependent GMPpNp binding activity of $\mathrm{T}$.

were affected by the protein microenvironment surrounding the modification sites.

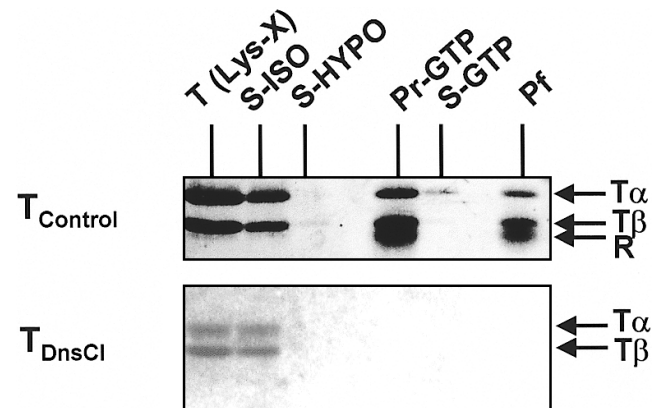

Fig. 2. Sedimentation assay of $\mathrm{T}$ or DnsCl-modified $\mathrm{T}$ in the presence of illuminated urea-washed ROS membranes. Samples of $\mathrm{T}$, either labeled or not labeled with $\mathrm{DnsCl}$, were incubated with photostimulated urea-washed ROS membranes. Following SDS-PAGE, the supernatants and pellets, yielded by the sedimentation assay described under Materials and Methods, were analyzed by silver staining. $\mathrm{T}_{\mathrm{CONTROL}}$, unlabeled $\mathrm{T} ; \mathrm{T}_{\text {DnsCl }}$, DnsCl-modified $\mathrm{T}$. The fractions that were obtained from the $\mathrm{T}_{\text {CONTRoL }}$ sample were boiled for $1 \mathrm{~min}$ prior to separation by gel electrophoresis. The fractions that were obtained from the $\mathrm{T}_{\mathrm{DnsCl}}$ sample were extensively boiled previous to the electrophoresis separation in order to induce the formation of high molecular weight aggregates of $\mathrm{R}$.

We also performed parallel labeling experiments using $\mathrm{R}$ to examine the effect of the $\mathrm{DnsCl}$ treatment on its ability to activate T. As shown in Fig. 1c, when R was incubated with $5 \mathrm{mM}$ of $\mathrm{DnsCl}$, the treatment did not affect its ability to catalyze the light-induced guanine nucleotide exchange reaction of $\mathrm{T}$.

Interaction between $\mathbf{R}$ and DnsCl-labeled $\mathbf{T}$ DnsClmodified $\mathrm{T}$ was incubated with urea-washed ROS membranes under room light. Various washes were also performed, as described under Materials and Methods. Following centrifugation, the components of each washing step were separated by SDS-PAGE and visualized by silver staining. As illustrated in Fig. 2 ( $\mathrm{T}_{\text {DnsCl }}$ ), the modification of $\mathrm{T}$ with $\mathrm{DnsCl}$ hindered its binding to $\mathrm{R}^{*}$. The labeled protein was recovered in the supernatant following the first centrifugation (S-ISO). In contrast, the unmodified $\mathrm{T}$ behaved as expected (Fig. 2, $\left.\mathrm{T}_{\text {CONTROL }}\right)$. After reconstitution, approximately $70 \%$ of the original $\mathrm{T}$ became tightly bound to the bleached-washed ROS membranes (Pr-GTP). Isotonic and hypotonic washing steps (S-ISO and S-HYPO) were performed to eliminate the excess of $\mathrm{T}$ that did not specifically interact with $\mathrm{R}^{*}$. Bound $\mathrm{T}$ partially dissociated from the membranes following incubation with GTP (S-GTP). Since about five extractions with the buffer containing GTP were generally required in order to entirely remove $\mathrm{T}$ from the photoexcited ROS membranes (data not included), some of the bound $\mathrm{T}$ remained attached to the Pf fraction following one wash with this solution. A second control experiment containing $\mathrm{T}$ that was incubated with $\mathrm{DnsCl}$, which had been titrated with 30 $\mathrm{mM}$ lysine and $20 \mathrm{mM} \beta$-mercaptoethanol, showed an 


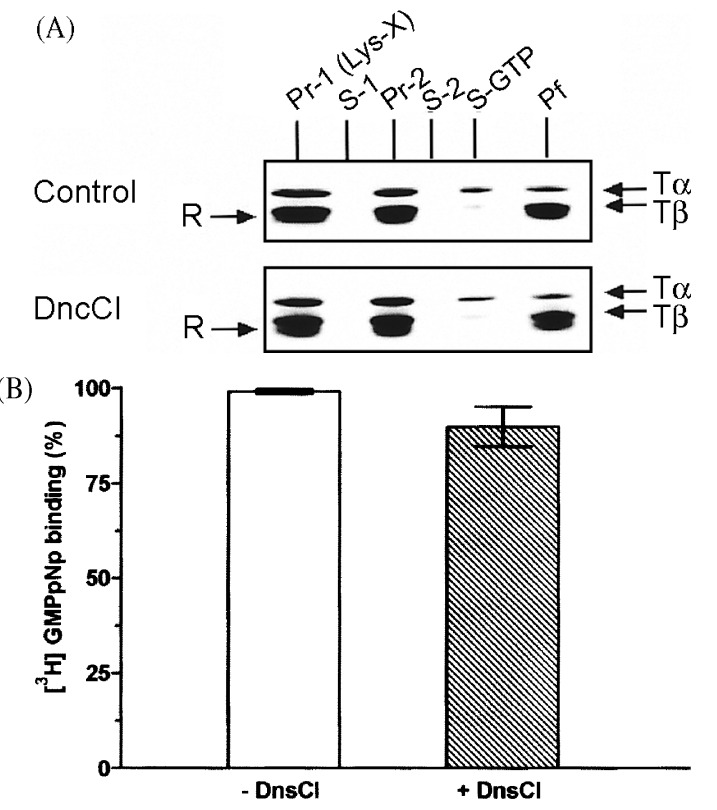

Fig. 3. $T$ functionality in $T: R^{*}$ complexes treated with DnsCl. (A) $\mathrm{T}: \mathrm{R}^{*}$ complexes were incubated with or without $\mathrm{DnsCl}$ (DnsCl or Control, respectively). The supernatants and pellets that were obtained by various washes were analyzed by SDSPAGE. The polypeptide bands were visualized by silver staining. In both cases, the fractions were boiled for $1 \mathrm{~min}$ prior to the electrophoresis separation. (B) GMPpNp binding activity of $\mathrm{T}$ in $\mathrm{T}: \mathrm{R}^{*}$ complexes treated with DnsCl. An aliquot of the Pr-1 (Lys-X) fraction that was obtained from $\mathrm{T}: \mathrm{R}^{*}$ complexes that were incubated with DnsCl was examined for its remaining GMPpNp binding activity $(+\mathrm{DnsCl})$. A sample of the corresponding fraction that was obtained from the $\mathrm{T}: \mathrm{R}^{*}$ complexes that were incubated without $\mathrm{DnsCl}$ was included as a control experiment (-DnsCl).

electrophoretic pattern that was identical to the untreated $\mathrm{T}$ (data not shown). Comparable gels were electrotransferred to nitrocellulose filters, and immunoanalyzed with polyclonal antibodies against $\mathrm{T}$. Identical results were obtained (data not included).

Functionality of $\mathbf{T}$ in illuminated $\mathbf{T}: \mathbf{R}$ complexes subjected to modification with DnsCl $\mathrm{T}$ was incubated with urea-washed ROS membranes under room light to form the $\mathrm{T}: \mathrm{R}^{*}$ complex. $\mathrm{T}: \mathrm{R}^{*}$ was then treated with $\mathrm{DnsCl}$ to assess whether $\mathrm{R}^{*}$ was capable of protecting against the observed $\mathrm{DnsCl}$ inhibition in the guanine nucleotide binding activity of T. Washes were performed to evaluate the ability of $\mathrm{T}$ to dissociate from these complexes in the presence of GTP. The components of these washes were separated by SDSPAGE, and the polypeptide pattern was visualized by silver staining. Although some of the bound T remained attached to the Pf fraction after one wash with the solution containing GTP, T was eluted with GTP from the ROS membranes in the untreated $\mathrm{T}: \mathrm{R}^{*}$ complex (S-GTP) (Fig. 3a, control). As expected, the other control experiment, in which $\mathrm{T}: \mathrm{R}^{*}$ was

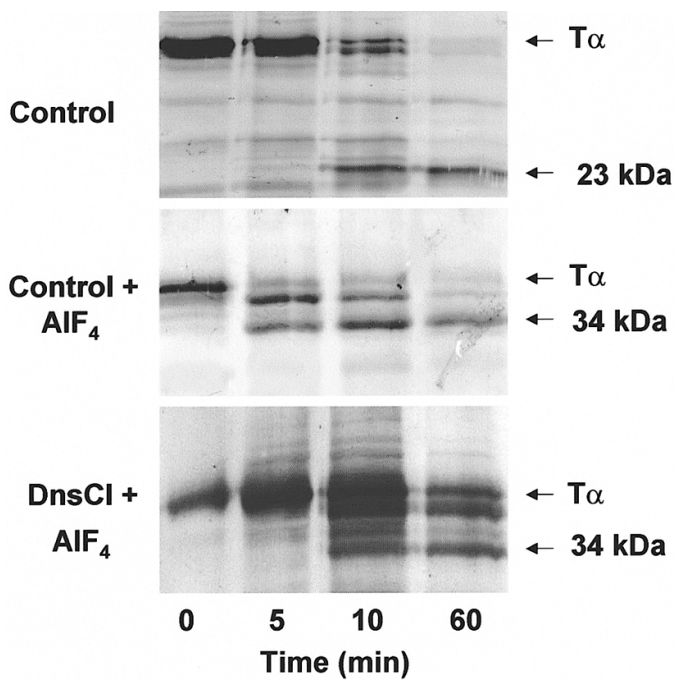

Fig. 4. Limited proteolysis studies on the conformation of untreated and DnsCl-treated T. At the indicated time intervals, the resulting fragments were resolved by SDS-PAGE and visualized by immunoblotting with anti-T polyclonal antibodies that preferentially recognize $\mathrm{T}_{\alpha}$. When $\mathrm{T}$ is in the inactive conformation, $\mathrm{T}_{\alpha}$-GDP is cleaved by trypsin into a fragment of $23 \mathrm{kDa}$ (Control). By contrast, when $\mathrm{T}$ is activated by fluoroaluminate, $\mathrm{T}_{\alpha}{ }^{-} \mathrm{GDP}-\mathrm{AlF}_{4}^{-}$is cleaved into a fragment of 34 $\mathrm{kDa}$ that resists further proteolysis $\left(\mathrm{Control}+\mathrm{AlF}_{4}\right)$. The tryptic pattern of DnsCl-modified $\mathrm{T}$, following the addition of fluoroaluminate, is similar to that observed for the active conformation of $\mathrm{T}\left(\mathrm{DnsCl}+\mathrm{AlF}_{4}\right)$.

incubated with DnsCl that was previously titrated with $30 \mathrm{mM}$ lysine and $20 \mathrm{mM} \beta$-mercaptoethanol, showed the same pattern as the untreated $\mathrm{T}: \mathrm{R}^{*}$ sample (data not shown). Interestingly, the pattern for the DnsCl-treated $\mathrm{T}: \mathrm{R}^{*}$ complex was also identical in both control samples (Fig. 3a, DnsCl). T was liberated from the ROS membranes in the presence of GTP (S-GTP), suggesting that $\mathrm{R}^{*}$ protected against the inactivation of $\mathrm{T}$ by DnsCl. Alternatively, $\mathrm{T}$ was immunologically detected following electrotransfer of the gels to nitrocellulose filters showing identical results (data not included). Furthermore, when the GMPpNp binding activity of the DnsCl-treated $\mathrm{T}: \mathrm{R}^{*}$ sample was quantitatively determined, a complete protection against the inactivation of $\mathrm{T}$ by $\mathrm{DnsCl}$ was detected (Fig. 3b).

Protease protection assays of $\mathrm{T}$ and DnsCl-labeled $\mathrm{T}$ in the presence of fluoroaluminate Activated $\mathrm{T}_{\alpha}$ and $\mathrm{AlF}_{4}^{-}$-bound $\mathrm{T}_{\alpha}$ yielded identical protein fragments when incubated with trypsin (Bigay et al., 1985, 1987); therefore, the protease protection assays of $\mathrm{T}$ in the presence of $\mathrm{AlF}_{4}^{-}$have been widely used to study the light-independent activation of the protein (García et al., 1995; Natochin and Artemyev, 2000). The resulting tryptic polypeptide patterns (obtained for untreated $\mathrm{T}$ and DnsCl-modified $\mathrm{T}$ in the presence of $\mathrm{AlF}_{4}^{-}$) were assessed by Western blot analyses using anti- $\mathrm{T}$ 


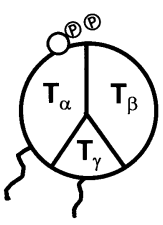

(A)

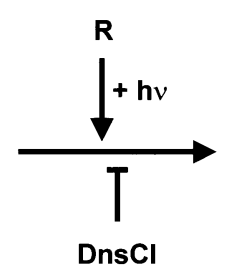

DnsCl

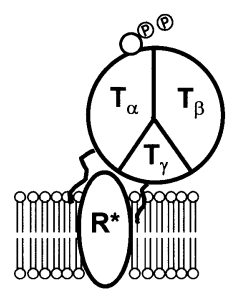

(B)
Fig. 5. Effects of DnsCl on the R binding activity of T. (A) The GDP-bound heterotrimeric $\mathrm{T}$ with its three subunits $\left(\mathrm{T}_{\alpha}, \mathrm{T}_{\beta}\right.$, and $\mathrm{T}_{\gamma}$ ). (B) The interactions of $\mathrm{T}$ with $\mathrm{R}^{*}$ and the membrane lipid bilayer. The acyl groups of $\mathrm{T}_{\alpha}$ and $\mathrm{T}_{\gamma}$ are shown interacting with the membrane. The modification of $\mathrm{T}$ with $\mathrm{DnsCl}$ hinders its

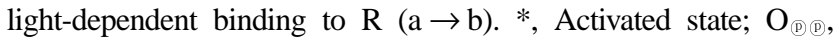
GDP; hv, light.

polyclonal antibodies that preferentially recognize $T_{\alpha}$. Figure 4 shows that a trypsin-resistant fragment of $34 \mathrm{kDa}$ appeared when the untreated $\mathrm{T}$ sample was supplemented with $\mathrm{AlF}_{4}^{-}$ $\left(\right.$ control $\left.+\mathrm{AlF}_{4}\right)$. Trypsin protection was also observed when fluoroaluminate was added to the DnsCl-labeled $\mathrm{T}$ sample (Fig. 4, DnsCl $+\mathrm{AlF}_{4}$ ). On the contrary, the inactive $\mathrm{T}$ sample showed a lower migrating tryptic polypeptide band of approximately $23 \mathrm{kDa}$ (Fig. 4, control). These results indicate that $\mathrm{AlF}_{4}^{-}$is capable of mimicking the transitional state of $\mathrm{T}$ in the DnsCl-labeled sample. Although similar results were obtained when the gels were silver stained, the presence of tryptic polypeptides from $T_{\beta}$ blurred and slightly buried the resulting fragments from $\mathrm{T}_{\alpha}$ (data not shown).

\section{Discussion}

As illustrated in Fig. 5, the modification of $\mathrm{T}$ with DnsCl blocked the productive interaction of $\mathrm{T}$ to $\mathrm{R}^{*}(\mathrm{a} \rightarrow \mathrm{b})$. Since a physical association between $\mathrm{R}^{*}$ and $\mathrm{T}$ represents the initial requisite for the $\mathrm{T}$ nucleotide exchange reaction to take place, the inactivation in GMPpNp binding activity that is observed in DnsCl-modified $\mathrm{T}$ can be attributed to a hindrance at this step of the pathway. In view of the fact that no effect was observed on the ability of DnsCl-treated $\mathrm{R}$ to activate $\mathrm{T}$, it appears that DnsCl introduces structural changes in the general folding of $\mathrm{T}$ that either sterically prevents its direct binding to $\mathrm{R}^{*}$ or physically hinders the conformational changes in this protein that is required to bind to $\mathrm{R}^{*}$. Several $\mathrm{T}$ regions have been implicated in the $\mathrm{R}$ contact, which include $\mathrm{T}_{\alpha}$ amino acids $340-350$ on the COOH-terminus, $310-323$, in the $\alpha$ helix $4 / \beta$ strand $6 / \alpha$ helix 5 region and 9-23 on the $\mathrm{NH}_{2-}$ terminus, as well as the $\mathrm{COOH}$-terminal tail of $\mathrm{T}_{\gamma}$ that contains the farnesylated residues (Hamm et al., 1988; Kisselev et al., 1994, 1995, 1999; García et al., 1995; Osawa and Weiss, 1995; Lichtarge et al., 1996; Martin et al., 1996; Mazzoni and Hamm, 1996; Onrust et al., 1997; Fahmy, 1998; Nishimura et al., 1998; Bubis et al., 2001). Yang et al. (1999) noticed that conformational changes, taking place at the Ctermini of $\mathrm{T}_{\alpha}$ during G-protein activation, might be important for the allosteric communication between the receptor binding and GDP-binding sites on the molecule. Furthermore, synthetic peptides from the $\mathrm{C}$ termini of $\mathrm{T}_{\alpha}$ and $\mathrm{T}_{\gamma}$ recognize $\mathrm{R}^{*}$ with similar affinity and can replace the holoprotein in stabilizing the active metarhodopsin II photointermediate. Interestingly, although both the $\mathrm{C}$-terminal regions of $\mathrm{T}_{\alpha}$ and $\mathrm{T}_{\gamma}$ have been localized to a common surface of $\mathrm{T}$ by X-ray studies (Lambright et al., 1996), the distance between these two regions in GDP-bound T appears too long to interact with the same site in $\mathrm{R}$. This suggests that the signal transfer from $\mathrm{R} *$ to $\mathrm{T}$ takes place by a two-site sequential mechanism, in which nucleotide exchange catalysis relies on the geometry of interaction in matching pairs of at least two sites between $\mathrm{R}$ and T (Kisselev et al., 1999). All of these T regions contain lysines: (i) $\mathrm{Lys}_{341}$ and $\mathrm{Lys}_{345}$ are situated at the $\mathrm{COOH}$-terminal tail of $\mathrm{T}_{\alpha}$; (ii) $\mathrm{Lys}_{313}$ is located at the region of $\mathrm{T}_{\alpha}$, flanked by amino acids 310 and 323; (iii) $\mathrm{Lys}_{10}, \mathrm{Lys}_{17}, \mathrm{Lys}_{18}, \mathrm{Lys}_{20}$ and $\mathrm{Lys}_{25}$ are found at the $\mathrm{T}_{\alpha} \mathrm{NH}_{2}$-terminal; and (iv) $\mathrm{Lys}_{61}, \mathrm{Lys}_{65}$, and $\mathrm{Lys}_{68}$ are positioned on the $\mathrm{T}_{\gamma} \mathrm{COOH}$-terminus. Although the specific residues that are modified by $\mathrm{DnsCl}$ were not localized in the primary $\mathrm{T}$ structure, a spectrophotometric analysis showed that about $2-3 \mathrm{~mol}$ of $\mathrm{DnsCl}$ were incorporated per mole of T. Plausibly, the modification by $\mathrm{DnsCl}$ of any of these lysine residues of $\mathrm{T}$ will prevent the successful association of the protein with $\mathrm{R}$.

In order to explore the ability of $\mathrm{R}$ to protect against the inactivation that was observed in the $\mathrm{T}$ function, the chemical modifications with DnsCl were carried out on preformed $\mathrm{T}: \mathrm{R}^{*}$ complexes. The functional assays that were performed on the DnsCl-treated $\mathrm{T}: \mathrm{R}^{*}$ samples showed that $\mathrm{R}^{*}$ completely protected against the inactivation of $\mathrm{T}$ by $\mathrm{DnsCl}$. Trypsin protection assays of $\mathrm{T}$, in the presence of fluoroaluminate, have been employed to measure the ability of $\mathrm{T}$ to undergo a conformational change to the active state in a light-independent manner. Since the reported trypsin protection was observed when $\mathrm{AlF}_{4}^{-}$was added to the DnsCllabeled $\mathrm{T}$, then the residues that were modified by $\mathrm{DnsCl}$ in the protein must not be located in the magnesium and/or guanine nucleotide-binding region.

We previously reported that several lysine modification reagents such as o-phtalaldehyde, acetic anhydride, citraconic anhydride, and $\mathrm{DnsCl}$ inhibited the GTP binding activity of T by more than $60 \%$ (Bubis et al., 1995). Interestingly, DnsCl was the compound that generated the greatest inhibition $(\geq$ 90\%) (Bubis et al., 1995). Additionally, PLP, a reagent that was utilized to modify lysines on enzymes that bind phosphorylated substrates, also inhibited the T GMPpNp binding capability and was efficiently employed as an affinity label for the guanine nucleotide-binding site of the protein (Jaffé and Bubis, 2002). The results obtained here after treatment of $\mathrm{T}$ with $\mathrm{DnsCl}$ were consistent with our previous findings using PLP and other lysyl-specific probes. However, the lysine residue(s) that is modified on $\mathrm{T}$ by each reagent 
evidently must be different, since DnsCl blocked the association of $\mathrm{T}$ with $\mathrm{R}^{*}$ and PLP labeled the protein active site. In contrast, when fluorescein 5'-isothiocyanate was employed to modify the lysine residues of $\mathrm{T}$, no effect on the $\mathrm{T}: \mathrm{R}$ interaction or on the binding of GMPpNp to $\mathrm{T}$ was obtained (Hingorani and Ho, 1987). Similarly, phenyl isothiocyanate produced no effect on the GTP binding capability of T (Bubis et al., 1995). On the other hand, fluorescein 5'-isothiocyanate labeling affected the GTP hydrolytic activity as well as the GTP-induced conformational change of $\mathrm{T}_{\alpha}$, which ultimately led to the activation of cGMP phosphodiesterase (Hingorani and Ho, 1987). All of these observations suggest the existence of different functional lysines on $\mathrm{T}$ that are either located in the proximity of the interaction site with the photoreceptor protein, near the magnesium and guanine nucleotide binding sites in regions involved in the structural changes taking place upon protein activation, or near the contact region with cGMP phosphodiesterase. Consequently, with the use of a battery of these group-specific reagents, it seems plausible to "freeze" $\mathrm{T}$ in various particular conformational states of its G-protein cycle, which can be of great importance for interested crystallographers. The use of these reagents may also provide excellent conditions for studying several of the initial steps of the visual process in more detail.

Acknowledgments This work was supported by a grant from FONACIT, No S1-2000000514, Caracas, Venezuela.

\section{References}

Baylor, D. A. (1996) How photons start vision. Proc. Natl. Acad. Sci. USA 93, 560-565.

Berman, D. M., Kozasa, T. and Gilman, A. G. (1996) The GTPase-activating protein RGS4 stabilizes the transition state for nucleotide hydrolysis. J. Biol. Chem. 271, 27209-27212.

Bigay, J., Deterre, P., Pfister, C. and Chabre, M. (1985) Fluoroaluminates activate transducin-GDP by mimicking the $\gamma$ phosphate of GTP in its binding site. FEBS Lett. 191, 181-185.

Bigay, J., Deterre, P., Pfister, C. and Chabre, M. (1987) Fluoride complexes of aluminum or beryllium act on G-proteins as reversibly bound analogues of the $\gamma$ phosphate of GTP. EMBO J. 6, 2907-2913.

Bockaert, J. and Pin, J. P. (1999) Molecular tinkering of G protein-coupled receptors: an evolutionary success. EMBO J. 18, 1723-1729.

Bradford, M. M. (1976) A rapid and sensitive method for the quantitation of microgram quantities of protein utilizing the principle of protein-dye binding. Anal. Biochem. 72, 248-254.

Bubis, J. (1995) Improved purification of transducin subunits from bovine retinal rod outer segments. Biol. Res. 28, 291-299.

Bubis, J. (1998) Effect of detergents and lipids on transducin photoactivation by rhodopsin. Biol. Res. 31, 59-71.

Bubis, J. and Khorana, H. G. (1990) Sites of interaction in the complex between $\beta$ - and $\gamma$-subunits of transducin. J. Biol. Chem. 265, 12995-12999.
Bubis, J., Millan, E. J. and Martinez, R. (1993) Identification of guanine nucleotide binding proteins from Trypanosoma cruzi. Biol. Res. 26, 177-188.

Bubis, J., Ortiz, J. O. and Möller, C. (2001) Chemical modification of transducin with iodoacetic acid: transducin- $\alpha$ carboxymethylated at $\mathrm{Cys}_{347}$ allows transducin binding to lightactivated rhodopsin but prevents its release in the presence of GTP. Arch. Biochem. Biophys. 395, 146-157.

Bubis, J., Ortiz, J. O., Möller, C. and Millán, E. J. (1995) Identification and characterization of transducin functional cysteines, lysines, and acidic residues by group-specific labeling and chemical cross-linking; in Methods in Protein Structure Analysis, Atassi, M. Z. and Appella, E. (eds.), pp. 227-250, Plenum Press, New York, USA.

Carman, C. V. and Benovic, J. L. (1998) G-protein-coupled receptors: turn-ons and turn-offs. Curr. Opin. Neurobiol. 8, 335344.

Chen, F. and Lee, R. (1997) Phosducin and $\beta \gamma$-transducin interaction I: effects of post-translational modifications. Biochem. Biophys. Res. Commun. 233, 370-374.

Chen, R. F. (1968) Dansyl labeled proteins: determination of extinction coefficient and number of bound residues with radioactive dansyl chloride. Anal. Biochem. 25, 412-416.

Coleman, D. E., Berghuis, A. M., Lee, E., Linder, M. E., Gilman, A. G. and Sprang, S. R. (1994) Structures of active conformations of Gial and the mechanism of GTP hydrolysis. Science 265, 1405-1412.

Du, H., Fuh, R. A., Li, J., Corkan, A. and Lindsey, J. S. (1998) PhotochemCAD: a computer-aided design and research tool in photochemistry. Photochem. Photobiol. 68, 141-142.

Fahmy, K. (1998) Binding of transducin and transducin-derived peptides to rhodopsin studies by attenuated total reflectionFourier transform infrared difference spectroscopy. Biophys. $J$. 75, 1306-1318.

Garcia, P. D., Onrust, R., Bell, S. M., Sakmar, T. P. and Bourne, H. R. (1995) Transducin- $\alpha$ C-terminal mutations prevent activation by rhodopsin: a new assay using recombinant proteins expressed in cultured cells. EMBO J. 14, 4460-4469.

Hamm. H. E. (1998) The many faces of G protein signaling. $J$. Biol. Chem. 273, 669-672.

Hamm, H. E., Deretic, D., Arendt, A., Hargrave, P. A., Koenig, B. and Hofmann, K. P. (1988) Site of G protein binding to rhodopsin mapped with synthetic peptides from the a subunit. Science 241, 832-835.

Hargrave, P. A. (2001) Rhodopsin structure, function, and topography the Friedenwald lecture. Invest. Ophthalmol. Vis. Sci. 42, 3-9.

Hargrave, P. A., McDowell, J. H., Curtis, D. R., Wang, J. K., Juszczak, E., Fong, S.-L., Mohana Rao, J. K. and Argos, P. (1983) The structure of bovine rhodopsin. Biophys. Struc. Mech. 9, 235-244.

He, W., Cowan, C. W. and Wensel, T. G. (1998) RGS9, a GTPase accelerator for phototransduction. Neuron 20, 95-102.

Hingorani, V. N. and Ho, Y. -K. (1987) Chemical modification of bovine transducin: effect of fluorescein 5'-isothiocyanate labeling on activities of the transducin a subunit. Biochemistry 26, 1633-1639.

Jaffé, M. and Bubis, J. (2002) Affinity labeling of the guanine nucleotide binding site of transducin by pyridoxal 5'-phosphate. J. Protein Chem. 21, 339-348. 
Kisselev, O. G., Ermolaeva, M. V. and Gautam, N. (1994) A farnesylated domain in the $G$ protein $\gamma$ subunit is a specific determinant of receptor coupling. J. Biol. Chem. 269, 2139921402.

Kisselev, O., Pronin, A., Ermolaeva, M. and Gautam, N. (1995) Efficient interaction with a receptor requires a specific type of prenyl group on the $\mathrm{G}$ protein $\gamma$ subunit. Proc. Natl. Acad. Sci. USA 92, 9102-9106.

Kisselev, O. G., Meyer, C. K., Heck, M., Ernst, O. P. and Hofmann, K. P. (1999) Signal transfer from rhodopsin to the G-protein: evidence for a two-site sequential fit mechanism. Proc. Natl. Acad. Sci. USA 96, 4898-4903.

Laemmli, U. K. (1970) Cleavage of structural proteins during assembly of head bacteriophage T4. Nature 227, 680-685.

Lamb, T. D. (1996) Gain and kinetics of activation in the Gprotein cascade of phototransduction. Proc. Natl. Acad. Sci. USA 93, 566-570.

Lambright, D. G., Noel, J. P., Hamm. H. E. and Sigler, P. B. (1994) Structural determinants for activation of the $\alpha$-subunit of a heterotrimeric G protein. Nature 369, 621-628.

Lichtarge, O., Bourne, H. R. and Cohen, F. E. (1996) Evolutionarily conserved $\mathrm{G} \alpha \beta \gamma$ binding surfaces support a model of the G protein-receptor complex. Proc. Natl. Acad. Sci. USA 93, 7507-7511.

Makino, E. R., Handy, J. W., Li, T. and Arshavsky, V. Y. (1999) The GTPase activating factor for transducin in rod photoreceptors is the complex between RGS9 and type 5 G protein $\beta$ subunit. Proc. Natl. Acad. Sci. USA 96, 1947-1952.

Martin, E. L., Rens-Domiano, S., Schatz, P. J. and Hamm, H. E. (1996) Potent peptide analogues of a $G$ protein receptorbinding region obtained with a combinatorial library. J. Biol. Chem. 271, 361-366.

Mazzoni, M. R. and Hamm, H. E. (1996) Interaction of transducin with light-activated rhodopsin protects it from proteolytic digestion by trypsin. J. Biol. Chem. 271, 30034-30040.

Millán, E. J and Bubis, J. (2002) Identification of functionally important cysteines in the $\alpha$-subunit of transducin by chemical cross-linking techniques. J. Protein Chem. 21, 1-8.

Mixon, M. B., Lee, E., Coleman, D. E., Berghuis, A. M., Gilman, A. G. and Sprang, S. R. (1995) Tertiary and quaternary structural changes in Giol induced by GTP hydrolysis. Science 270, 954-960.

Nathans, J. and Hogness, D. S. (1983) Isolation, sequence analysis, and intron-exon arrangement of the gene encoding bovine rhodopsin. Cell 34, 807-814.

Natochin, M. and Artemyev, N. O. (2000) Mutational analysis of functional interfaces of transducin. Methods Enzymol. 315, 539554.

Nishimura, S., Kandori, H. and Maeda, A. (1998) Interaction between photoactivated rhodopsin and the C-terminal peptide of transducin $\alpha$-subunit studied by FTIR spectroscopy. Biochemistry 37, 15816-15824.

Noel, J. P., Hamm, H. E. and Sigler, P. B. (1993) The $2.2 \AA$ crystal structure of transducin- $\alpha$ complexed with GTP $\gamma \mathrm{S}$. Nature 366, 654-663.
Okada, T., Le Trong, I., Fox, B. A., Behnke, C. A., Stenkamp, R. E. and Palczewski, K (2000) X-ray diffraction analysis of three-dimensional crystals of bovine rhodopsin obtained from mixed micelles. J. Struct. Biol. 130, 73-80.

Onrust, R., Herzmark, P., Chi, P., Garcia, P. D., Lichtarge, O., Kingsley, C. and Bourne, H. R. (1997) Receptor and $\beta \gamma$ binding sites in the $\alpha$ subunit of the retinal $G$ protein transducin. Science 275, 381-384.

Ortiz, J. O. and Bubis, J. (2001) Effects of differential sulfhydryl group-specific labeling on the rhodopsin and guanine nucleotide binding activities of transducin. Arch. Biochem. Biophys. 387, 233-242.

Osawa, S. and Weiss, E. R. (1995) The effect of carboxyl-terminal mutagenesis of Gt $\alpha$ on rhodopsin and guanine nucleotide binding. J. Biol. Chem. 270, 31052-31058.

Ovchinnikov, Y. U. A. (1982) Rhodopsin and bacteriorhodopsin: structure-function relationships. FEBS Lett. 148, 179-191.

Palczewski, K., Kumasaka, T., Hori, T., Behnke, C. A., Motoshima, H., Fox, B. A., Le Trong, I., Teller, D. C., Okada, T., Stenkamp, R. E., Yamamoto, M. and Miyano, M. (2000) Crystal structure of rhodopsin: a G-protein-coupled receptor. Science 289, 739-745.

Pugh Jr, E. N., Nikonov, S. and Lamb, T. D. (1999) Molecular mechanisms of vertebrate photoreceptor light adaptation. Curr. Opin. Neurobiol. 9, 410-418.

Schertler, G. F. X., Villa, C. and Henderson, R. (1993) Projection structure of rhodopsin. Nature 362, 770-772.

Shichi, H. and Somers, R. L. (1978) Light-dependent phosphorylation of rhodopsin. Purification and properties of rhodopsin kinase. J. Biol. Chem. 253, 7040-7046.

Slep, K. C., Kercher, M. A., He, W., Cowan, C. W., Wensel, T. G. and Sigler, P. B. (2001) Structural determinants for regulation of phosphodiesterase by a $\mathrm{G}$ protein at $2.0 \AA$. Nature 409 , 1071-1077.

Tesmer, J. J., Berman, D. M., Gilman, A. G. and Sprang, S. R. (1997) Structure of RGS4 bound to $\mathrm{AlF}_{4}^{-}$-activated $\mathrm{G}_{\mathrm{i} \alpha 1}$ : stabilization of the transition state for GTP hydrolysis. Cell 89, 251-261.

Towbin, H., Staehlin, T. and Gordon, J. (1979) Electrophoretic transfer of proteins from polyacrylamide gels to nitrocellulose sheets: Procedure and some applications. Proc. Natl. Acad. Sci. USA 76, 4350-4354.

Unger, V. M., Hargrave, P. A., Baldwin, J. M. and Schertler, G. F. (1997) Arrangement of rhodopsin transmembrane $\alpha$-helices. Nature 389, 203-206.

Wald, G. and Brown, P. (1953) The molar extinction of rhodopsin. J. Gen. Physiol. 37, 189-200.

Wilkins, J. F., Bitensky, M. W. and Willardson, B. M. (1996) Regulation of the kinetics of phosducin phosphorylation in retinal rods. J. Biol. Chem. 271, 19232-19237.

Yang, C. -S., Skiba, N. P., Mazzoni, M. R. and Hamm, H. E. (1999) Conformational changes at the carboxyl terminus of $\mathrm{G} \alpha$ occur during $\mathrm{G}$ protein activation. J. Biol. Chem. 274, 23792385 . 